\title{
The use of SCADA system in water resources management, management of Shatt Al-Hilla in Iraq as a case study
}

\author{
Najm O. S. Alghazali ${ }^{1}$, Rafid M. Alkhaddar ${ }^{2}$, Humam A. Hadi ${ }^{1}$ \\ ${ }^{1}$ Babylon University, Engineering of College, Civil Engineering Department, Iraq \\ ${ }^{2}$ Water and Environmental Engineering, Liverpool John Moores University, School of the Built Environment, UK
}

\section{Emai address:}

dr.nalghazali@gmail.com(N. O. S. Alghazali),r.m.alkhaddar@ljmu.ac.uk(R. M. Alkhaddar), humamamer@yahoo.com(H. A. Hadi)

\section{To cite this article:}

Najm O. S. Alghazali, Rafid M. Alkhaddar, Humam A. Hadi. The Use of SCADA System in Water Resources Management, Management of Shatt Al-Hilla in Iraq as a Case Study. International Journal of Environmental Monitoring and Analysis.

Vol. 1, No. 5, 2013, pp. 237-247. doi: 10.11648/j.ijema.20130105.19

\begin{abstract}
The operation of hydraulic structures needs the presence of a number of specialists to make decisions to instantaneous takes actions at an appropriate time through controlling, monitoring, and giving a suitable warning for any undesirable cases like increasing water level higher than the normal level, stopping of any device. One of the monitoring tool is SCADA system which can allow the water manager to continuously compare the actual hydraulic state of the system with its optimal hydraulic state, and to take appropriate corrective steps as required .The proper application of the system in irrigation districts, can lead to improved water delivery service to farm, more effective operations, and in some cases a reduction in costs (less labor, less energy). In order to demonstrate the suitability of monitoring system such as the SCADA system, it was applied at Shatt Al-Hilla situates in Hilla city, $100 \mathrm{Km}$ south of Baghdad city in Iraq. It is the main channel that is branched from the left side of Euphrates River, just upstream the Hindiya Barrage. The system was applied at a33 $\mathrm{Km}$ reach from station $(0+000)$ to station $(33+000)$ and simulating the controlling of the head regulator at station $(0+000)$. SCADA system components consisted of a computer server as a master station, interface field data devices usually RTUs, or PLCs to allow interface between field sensing devices and local control switchboxes and gate actuators, communication system to transfer collected data and appropriate standards and or custom software. The hardware architecture of SCADA system was established for this reach and the controlling of the head regulator of Shatt Al-Hilla at sta. $(0+000)$ is simulated. The head regulator of Shatt Al-Hillawas run for three cases with six scenarios. The first case is for the daily discharges supplied to the head regulator for the year 2011, the second case is for the monthly water demanded to the head regulator (2011), and the third case is for the daily discharges that can be supplied to the head regulator for 2012 summer season .All cases and scenarios simulation produced good results except scenario (6) for the three cases because there are deficits in supplying the discharges in many days through the year, Also for case (2) there are deficits of $1.57 \%, 16.67 \%, 18.46 \%$, and $14.04 \%$ of the total demanded discharges for Mar., Apr., June, and July respectively.
\end{abstract}

Keywords: SCADA, PLC, Routing, HEC-RAS, Shatt Al-Hilla

\section{Introduction}

It is nowadays clear and well accepted that water resources are becoming scarce and, in the near future, will actually present one of the biggest problems that modern societies have to face. Water transport systems are difficult to manage and present low efficiencies in practice. As a result, an important percentage of water is lost; maintenance costs increase and water users follow a rigid irrigation schedule. All these problems can be reduced by automating the operation of irrigation canals.Irrigation is the largest water user in the world, using up to $85 \%$ of the available water in developing countries [1].

Real-time flow measurement and monitoring can be enhanced by the application of modern SCADA system in irrigation delivery and drainage projects. In open-channel applications, critical-depth flumes and weirs are common measurement devices [2]. They are convenient for SCADA application, since discharge can be computed from a single water level measurement. SCADA systems allow the water manager to continuously compare the actual hydraulic state of the system with its optimal hydraulic state, and to take 
appropriate corrective steps as required. SCADA allows the manager to react rapidly and effectively to the changing conditions.

The operation of hydraulic structures needs the presence of a number of specialists to make decisions that should be converted to instantaneous actions at an appropriate time. This research includes a solution for this problem by using SCADA system. This system enables management of water resources through controlling, monitoring, and giving a suitable warning for any undesirable cases like increasing water level higher than the normal level, stopping of any device, etc.

Supervisory control and data acquisition (SCADA) is a system that allows an operator to monitor and control processes that are distributed among various remote sites [3]. There are many processes using SCADA systems: hydroelectric, water distribution and treatment utilities, natural gas, etc. SCADA systems allow remote sites to communicate with a control facility and provide the necessary data to control processes. Beau and Charles[4] define SCADA system as a powerful tool which, when implemented properly in irrigation districts, can lead to improved water delivery service to farm, more effective operations, and in some cases a reduction in costs (less labor, less energy, etc.). Widespread adoptions of SCADA and automation technologies remain a technical and financial challenge for most irrigation districts.

SCADA can be traced to the development of telemetry from the first half of 20 th century $[3,5]$. Telemetry is the transmission and collection of data obtained by sensing real-time conditions. Since the early 1990's SCADA systems perform more operations automatically. The use of "smart" RTUs or PLCs (programmable logic controllers), which are capable of autonomously executing simple logic processes without involving the master computer, is increasing. SCADA systems are still to come into widespread infrastructural use in India. In this country they are being used primarily for automation in industrial production, and to some extent for specialized process control [6].

The objectives of the present research are: (1) presenting a detailed illustration on the SCADA System and its use in water resources management, (2) Establishing hardware architecture of SCADA system to Shatt Al-Hilla in Iraq (as a Case Study) from station $(0+000)$ to station $(33+000)$ and (3) Simulating the controlling of the head regulator of Shatt Al-Hilla at sta. $(0+000)$.

The SCADA System was installed in Shatt Al-Hilla. The controlling and monitoring of Shatt Al-Hillawere performed. The SCADA alarms were determined. From the results obtained from this study, several conclusions were obtained. Finally, recommendations for future studies were given.

\section{The Study Area}

Shatt Al-Hilla situates in Hilla city, $100 \mathrm{Km}$ south of Baghdad city in Iraq. It is the main channel that is branched from the left side of Euphrates River, just upstream the Hindiya Barrage[7]. It is the largest channel withdrawing water from the pool upstream the Hindiya Barrage. The reach considered of Shatt Al-Hilla has length of $33 \mathrm{Km}$ and starts from the intake point [head regulator of Shatt AlHilla at $\mathrm{Km}(00+000)]$ to the gauge station in Hilla city at $\mathrm{Km}(33+000)$. The hardware architecture of SCADA system was established for this reach and the controlling for the head regulator of Shatt Al-Hilla at sta. $(0+000)$ is simulated.

\section{Methodology}

\subsection{SCADA System Parts}

I. SCADA system components consisted of a computer server as a masterstation, interface field data devices usually RTUs, or PLCs to allow interface between field sensing devices and local control switchboxes and gate actuators, communication system to transfer collected data and appropriatestandards and or custom software

II. A central host computer server or servers (sometimes called a SCADA Center, master station, or Master Terminal Unit (MTU)).

III. One or more field data interface devices, usually RTUs, or PLCs, which interface to field sensing devices and local control switchboxes and gate actuators.

IV. Communications system which are used to transfer data between field data interface devices and control units and the computers in the SCADA central host. The system can be radio, telephone, cable, satellite, etc., or any combination of these.

V. A collection of standard and/or custom software [sometimes called Human Machine Interface (HMI) software or Man Machine Interface (MMI) software] systems which are used to provide the SCADA central host and operator terminal application, support the communications system, and monitor and control remotely located field data interface devices.

\subsection{Installing of SCADA System in Shatt Al-Hilla}

\subsubsection{The reach considered of Shatt Al-Hilla}

The reach considered of Shatt Al-Hilla has length of 33 $\mathrm{Km}$ and starts from the intake point [head regulator of Shatt Al-Hilla $\mathrm{Km}(00+000)]$ to the gauge station in Hilla city at $\mathrm{Km}(33+000)$. 


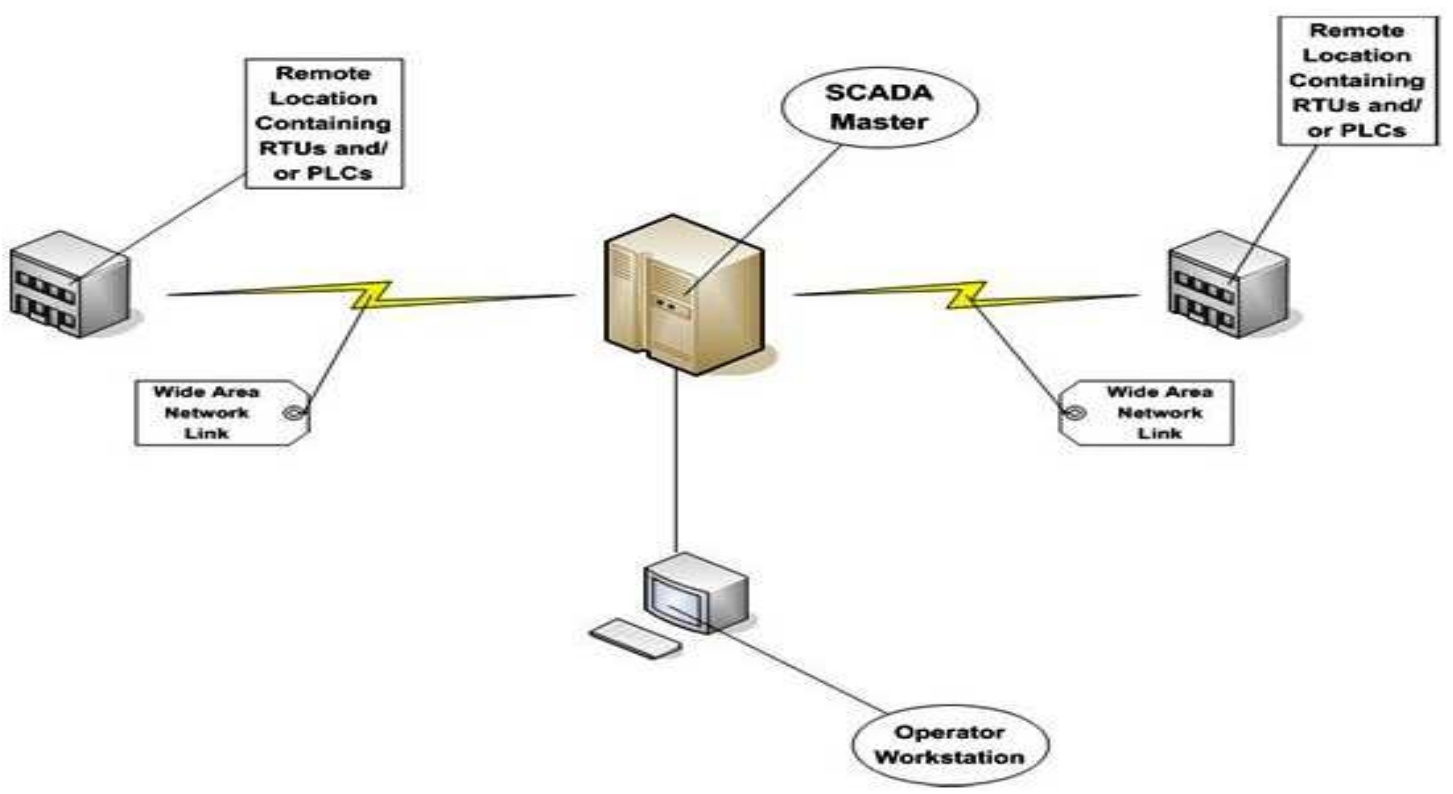

Fig. (1): Typical SCADA System [8]

\subsubsection{Hardware Architecture}

Field stations are the remote sites that should be connected to the main control room which is proposed to be at the city center of Baghdad. Field stations contain field instruments and equipment connected to devices being controlled and monitored. They convert physical parameters to electrical signals. Then these devices are connected to process controllers (PLCs). Process controllers control the field devices, operate the station automatically, gathering data from the field devices and provide data to the main control room. Main control room contains SCADA servers that store data from PLCs, regulate the control system, provide HMI for the operators and send SMS messages (Alarms) to the operator. The connection between the process controllers and the SCADA servers may be established using different techniques. Photo (1) shows the integrated SCADA system (laboratories of Liverpool John Moores University in UK (2011)). Figure (2) shows the hardware architecture of SCADA system to Shatt Al-Hilla.

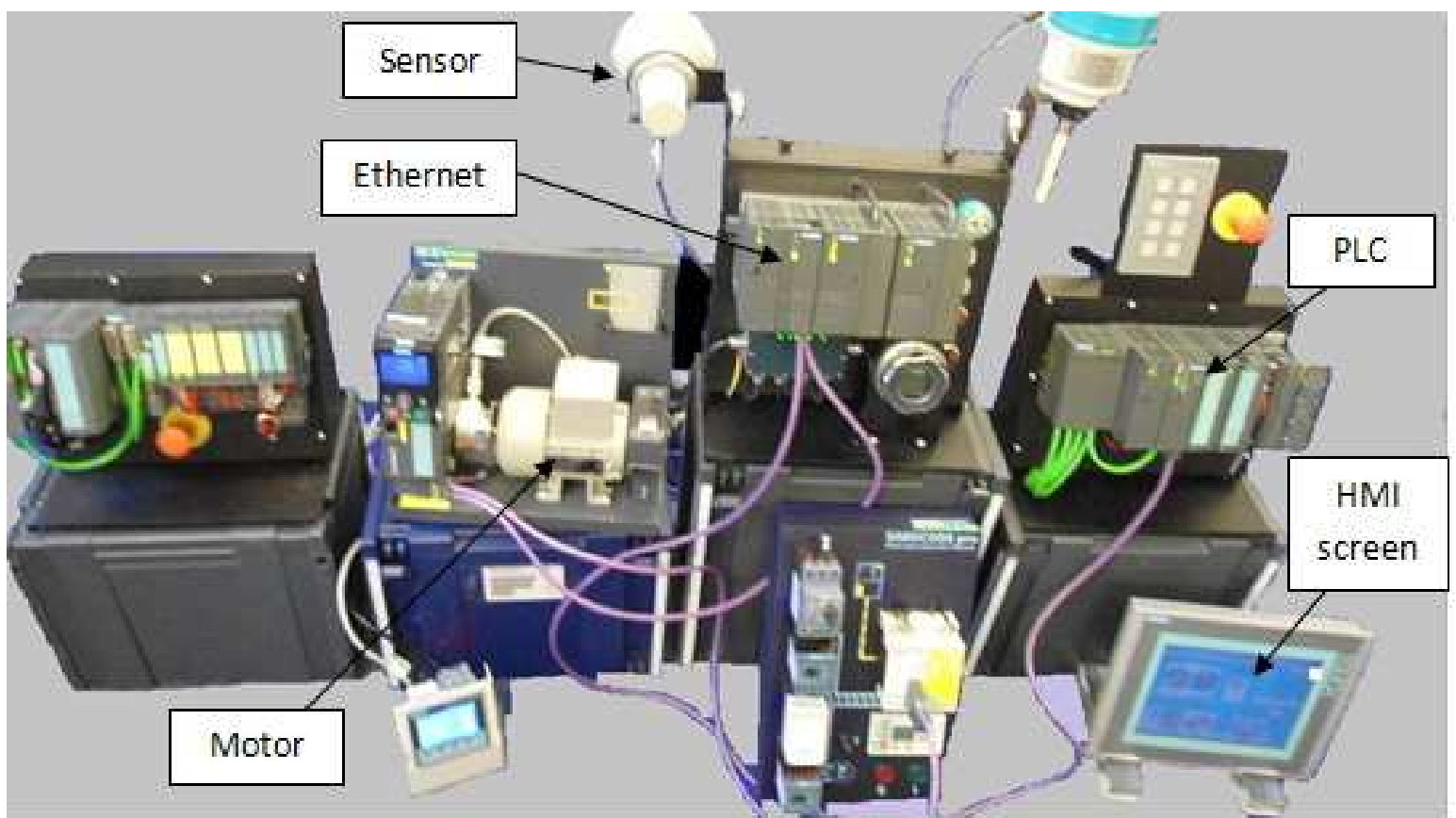

Photo (1): The integrated SCADA system (laboratories of Liverpool John Moores University in UK (2011)) 


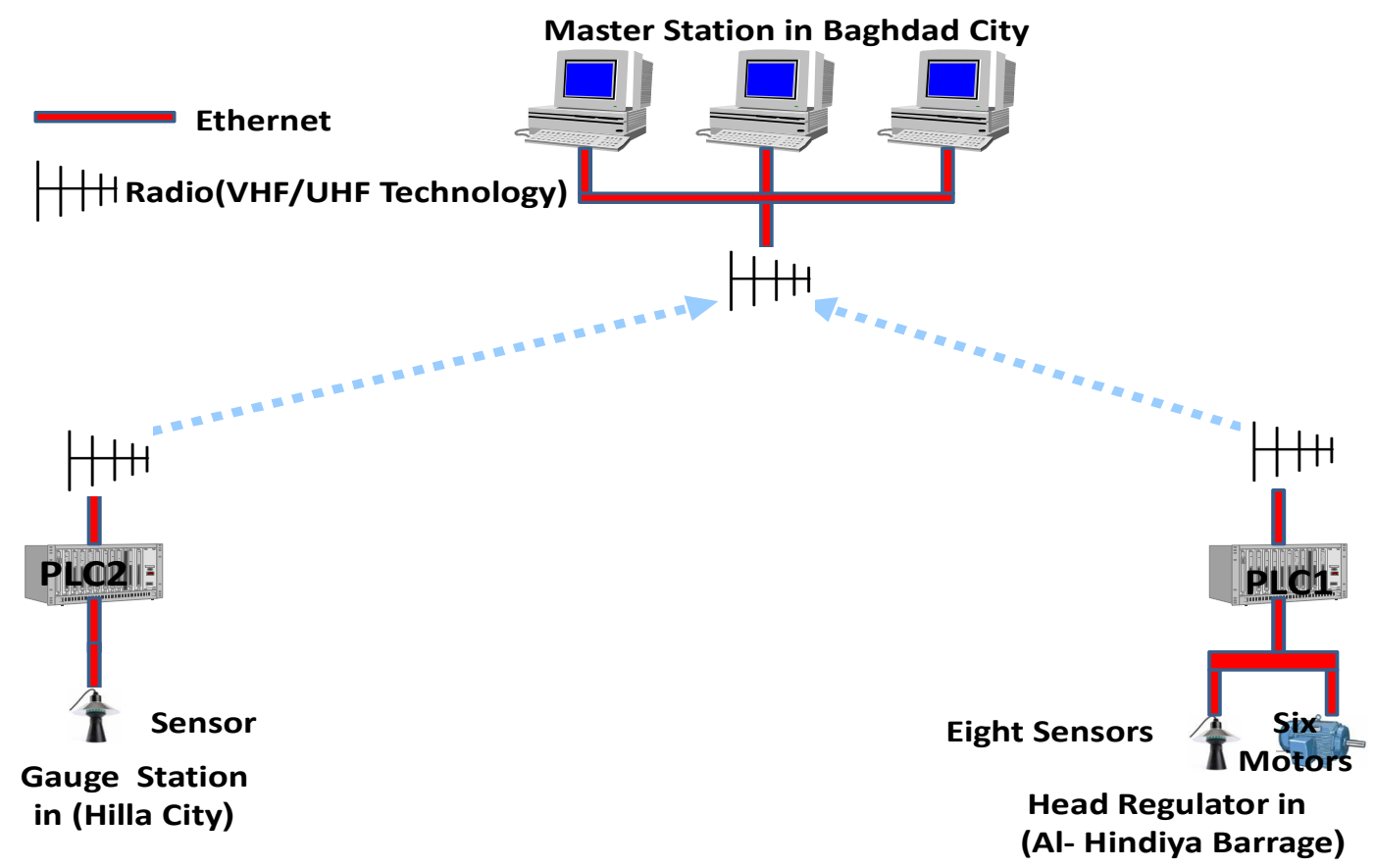

Fig. (2): Hardware architecture of SCADA system to Shatt Al-Hilla

\section{Analysis}

\subsection{Controlling of Shatt Al-Hilla}

Automatic control mode depends on the type of control algorithm that is used[9]. An algorithm that allows to control and measure variables is necessary to build up. The measured variable in this study is the water depth upstream the gate and the controlled variable is the gate opening. There are four types of control algorithms:

I. Direct control of a gate/offtake
II. Position controller of a gate/offtake

III. Upstream/downstream water depth control

IV. Offtake flow control

Position controller of a gate is used in the present study. Fig. (3)shows Positionsetpoint controller. The canal control has local control modes and the control program is installed in PLC1 in order to control the six gates of the head regulator of Shatt Al-Hilla. Typically, PLC1 should use a ladder-logic approach to programming due to its similarity to standard electrical circuits. The program needs to input a gate opening data ( $\mathrm{X}$ reference).

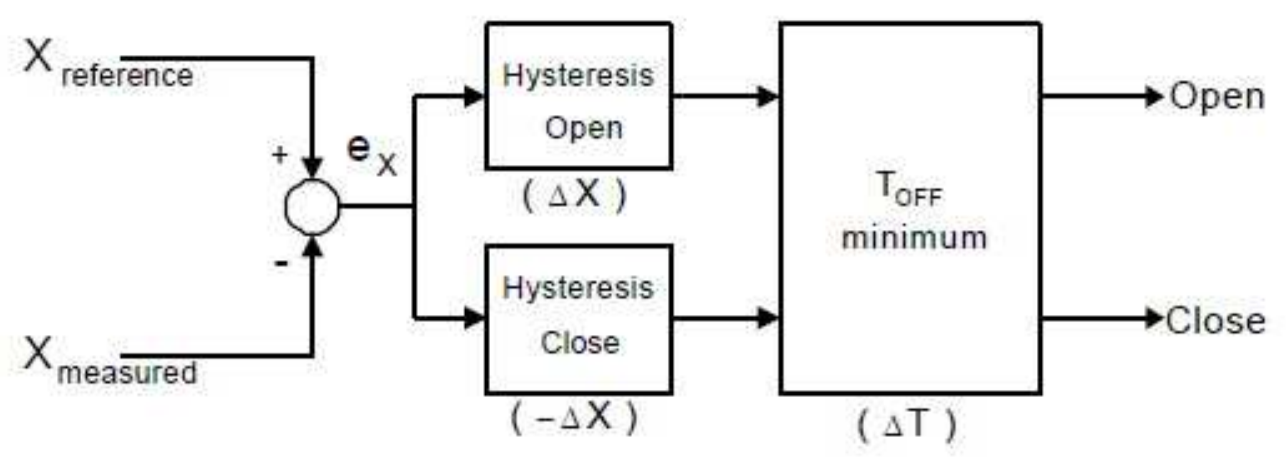

Fig. (3): Position setpoint controller[9]

Head regulator of Shatt Al-Hilla locates at Al-Hindiya Barrage[10].The radial gate flow is a type of variable area orifice flow, which may be either free or submerged [11]. However, accurate computation of radial gate flow requires complex analysis. The discharge under a radial gate is influenced by numerous parameters and structural dimensions. Fig. (4) shows a typical radial gate with raised sill an some of the variables that affect gate flow. The general equation (1) for flow through an undershot gate can be derived from Bernoulli equation [12] and is expressed as:

$$
Q=C_{d} C_{1} B w \sqrt{2 g y_{1}}
$$

Where:

$\mathrm{Q}=$ discharge (gate flow)

$\mathrm{C}_{\mathrm{d}}=$ coefficient of discharge

$\mathrm{C}_{1}=$ correction coefficient depends on the ratio of $\left(\mathrm{L} / \mathrm{P}_{1}\right)$ 
$\mathrm{W}=$ vertical gate opening

$\mathrm{B}=$ gate width

$\mathrm{g}=$ gravitational constant

$\mathrm{y}_{1}=$ water depth upstream the gate

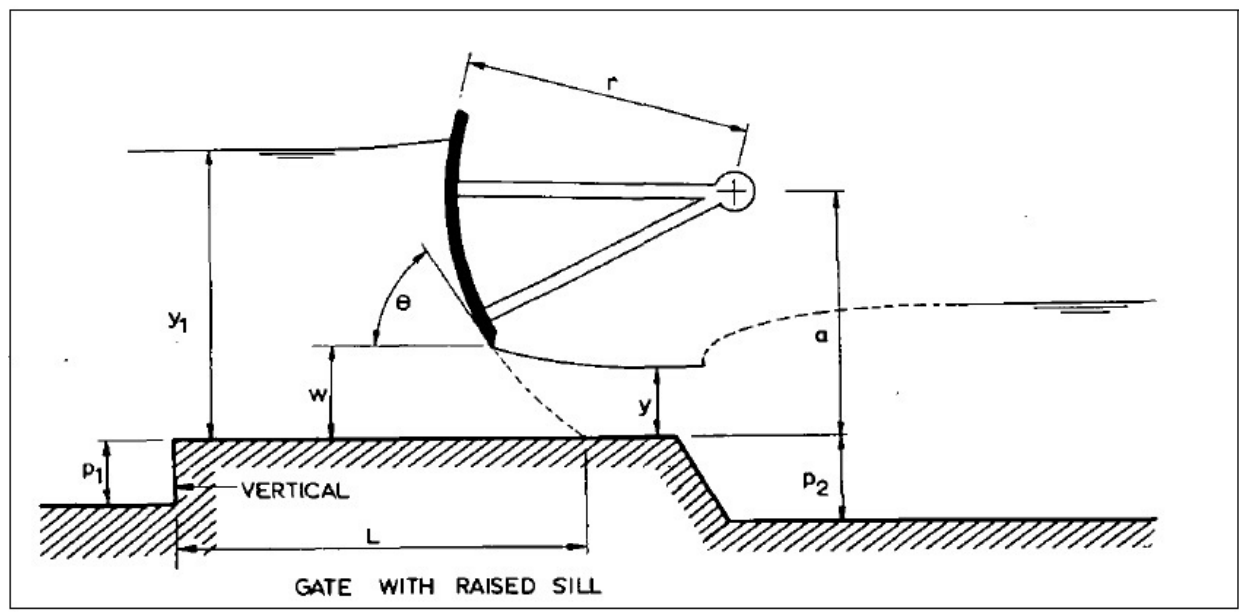

Fig. (4): Radial gate with raised sill showing calibration variables[13]

The coefficient $\mathrm{C}_{1}$ depends upon sill height $\left(\mathrm{P}_{1}\right)$ and the distance between the step and the gate seat $(\mathrm{L})$, as shown in
Fig. (4). It is a correction to $\left(C_{d}\right)$ for gate sills above streambed elevation. Its values are shown in Fig. (5).

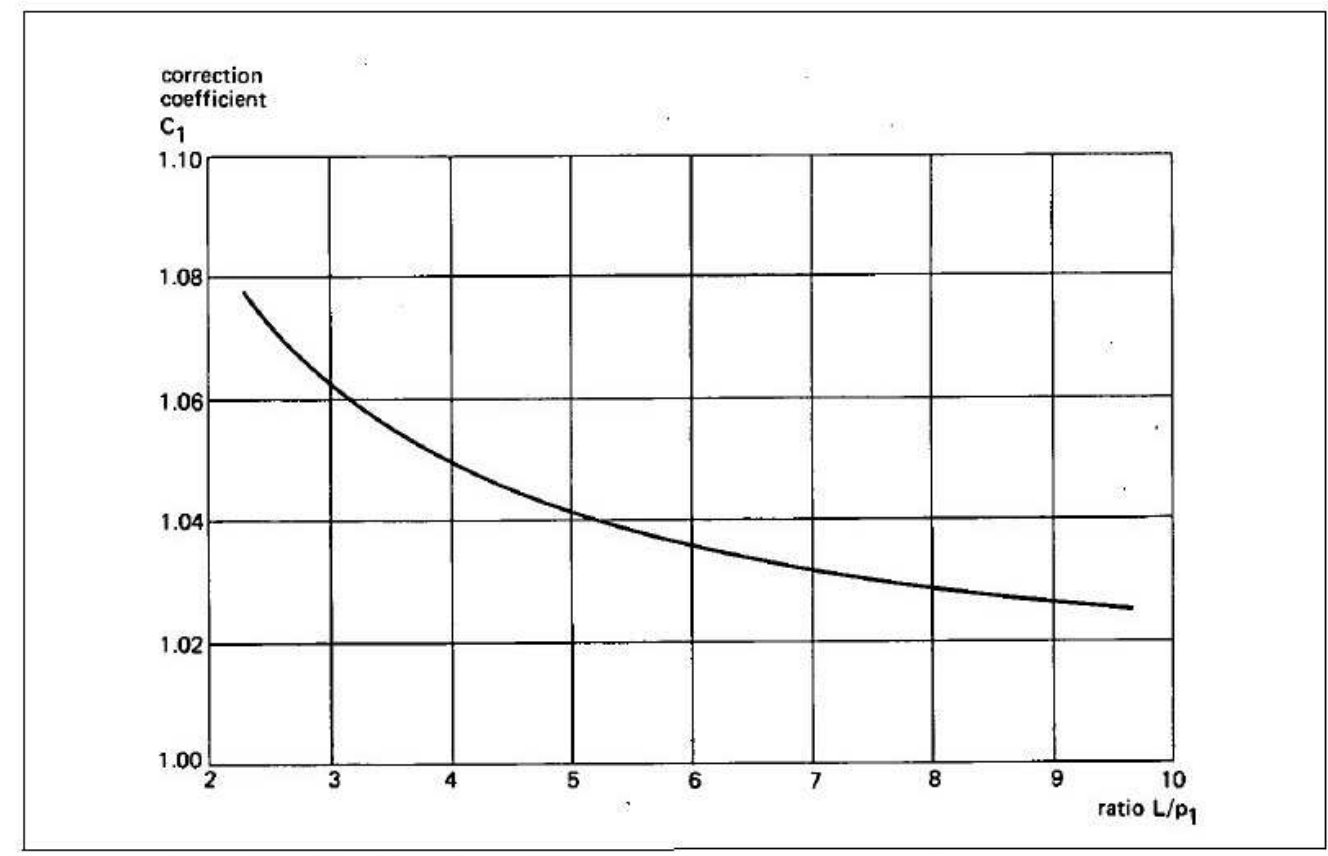

Fig. (5): $C_{I}$ values for radial gates with raised sill [12]

In order to control the six gates of the head regulator of Shatt Al-Hilla, a control program should be installed in PLC1.The difference between reference position (X reference) and actual position (X measured) gives the error (ex). The gateis opened when the error (ex) is positive and higher than the hysteresis $(\Delta x)$. The gate is closed when the error (ex) is negative and its absolute value is higher than the hysteresis $(\Delta x)$. Otherwise, there is no action for the gate. The hysteresis is a parameter that turns the controlling stable. Basically, the hysteresis is defined as an error range in which no action will be executed. The controller was unstable without hysteresis because the gate is opened and closed continuously. The hysteresis $(0.015 \mathrm{~m})$ is suitable to satisfy control action to any two sequence discharges. In order to protect the equipment from current peaks, there are time-out hardware requests to avoid consecutive starts without this minimum stop time. The time-out hardware used in this study is ( 1 day) because the control of head regulator of Shatt Al-Hilla is daily discharges. Canal operation concepts are based upon whether the water schedule priorities are supply or demand oriented. For this reason controlling the head regulator of Shatt Al-Hilla may be according to supply or demand oriented. In this study, three cases of controlling are taken: 
I. Case (1): according to supplied discharges through 2011.

II. Case (2): according to demanded discharges through 2011.

III. Case (3): according to discharges that can be supplied for the summer season 2012.

In each case, there are six scenarios depending on the number of working gates. These cases and scenarios are illustrated in Table (1).

Table (1): Cases and Scenarios of controlling of head regulator of Shatt Al- Hilla

\begin{tabular}{lllllll}
\hline Case No. & \multicolumn{2}{l}{ No. of working gates } & & & \\
& Scenario 1 & Scenario 2 & Scenario 3 & Scenario 4 & Scenario 5 & Scenario 6 \\
\hline $\mathbf{1}$ & 6 & 5 & 4 & 3 & 2 & 1 \\
$\mathbf{2}$ & 6 & 5 & 4 & 3 & 2 & 1 \\
$\mathbf{3}$ & 6 & 5 & 4 & 3 & 2 & 1 \\
\hline
\end{tabular}

From the results of controlling the head regulator of Shatt Al-Hilla, all cases and scenarios are acceptable and suitable for application except scenario (6) in the three cases because scenario (6) depends on working one radial gate and the maximum radial gate opening is $5.40 \mathrm{~m}$.

In case (2), the discharges for the four months Mar, Apr, June and July cannot satisfy the safe side because their discharges are higher than the maximum safe discharge $\left(247.05 \mathrm{~m}^{3} / \mathrm{s}\right)$. Therefore, there are deficits of $(1.57 \%$, $16.67 \%, 18.46 \%$, and $14.04 \%$ ) of the total demanded discharges for Mar, Apr, June, and July respectively.

\subsection{Monitoring of Shatt Al-Hilla}

SCADA system has the property of real-time remote

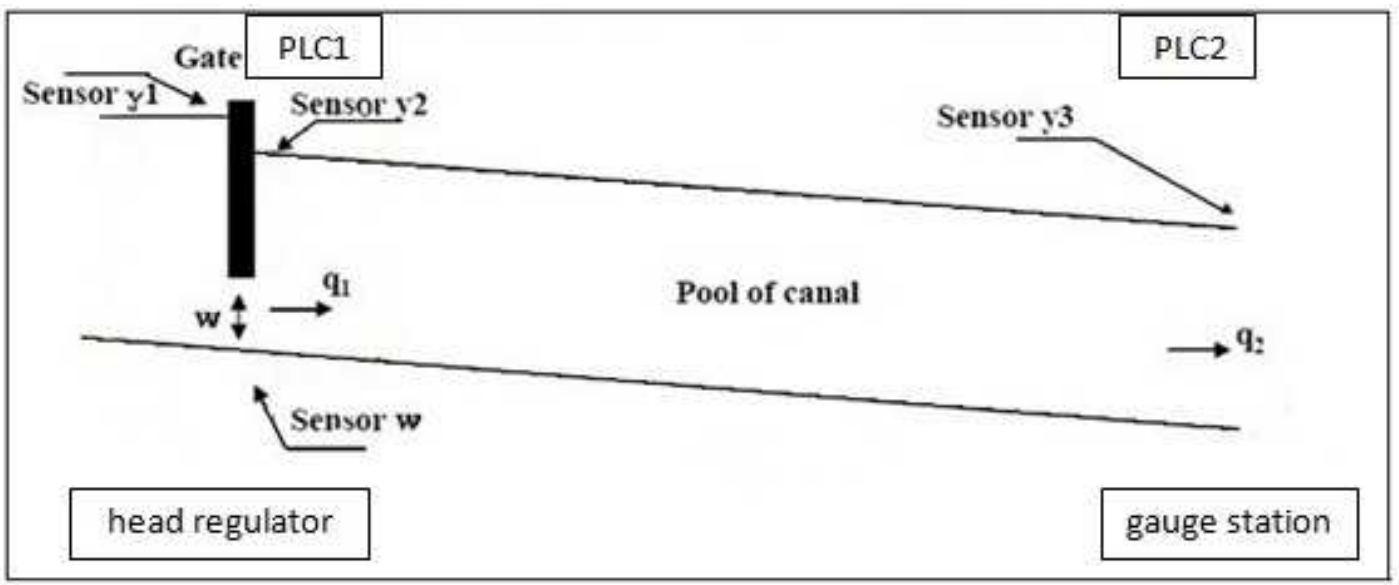

Fig.(6): The full monitoring diagram of Shatt Al- Hilla

\subsubsection{Shatt Al-Hilla HEC-RAS Model}

The Hydrologic Engineering Center River Analysis System (HEC-RAS) model [Version 4.1.0, (2010)] was developed by the U.S. Army Corps of Engineers. This software is a professional Engineering software package allows to perform one-dimensional steady flow and unsteady flow river hydraulics calculations [14]. It is used in the present study.

There are five main irrigation canals that withdraw water from the left side of Shatt Al-Hilla. In this study, the reach monitoring action in order to keep abreast of the hydraulic system conditions or in order to obtain its actual state. There are two PLCs (PLC 1 and PLC 2) in Fig. (5). PLC 1 receives water level information from the connected sensors (y1, y2 and w) and transmits it to the master station. PLC 2 receives water level information from the connected sensor (y3) and transmits it to the master station also. Fig. (6) illustrates the full monitoring diagram of Shatt Al-Hilla. The monitoring also enables operators to diagnose the losses of water from the main stream (due to any reason like illegal withdrawing) through a comparison of computed water level at downstream (PLC 2) in gauge station with the observed water level. 
In this study, the following boundary conditions are used in the numerical model:

I. Upstream boundary condition: the observed discharge hydrograph (shown in Fig. (8)) at the head regulator of Shatt Al-Hilla at station (1), which was measured at daily intervals, is used to define the upstream boundary condition for case (1).
II. Downstream boundary condition: the downstream boundary condition used in the numerical model is the rating curve at the last section (station $(33+000))$. Statistical analysis software CurveExpert 1.4 is used to find the best fit equation for the discharge-stage data at the last section (Fig. (9)).

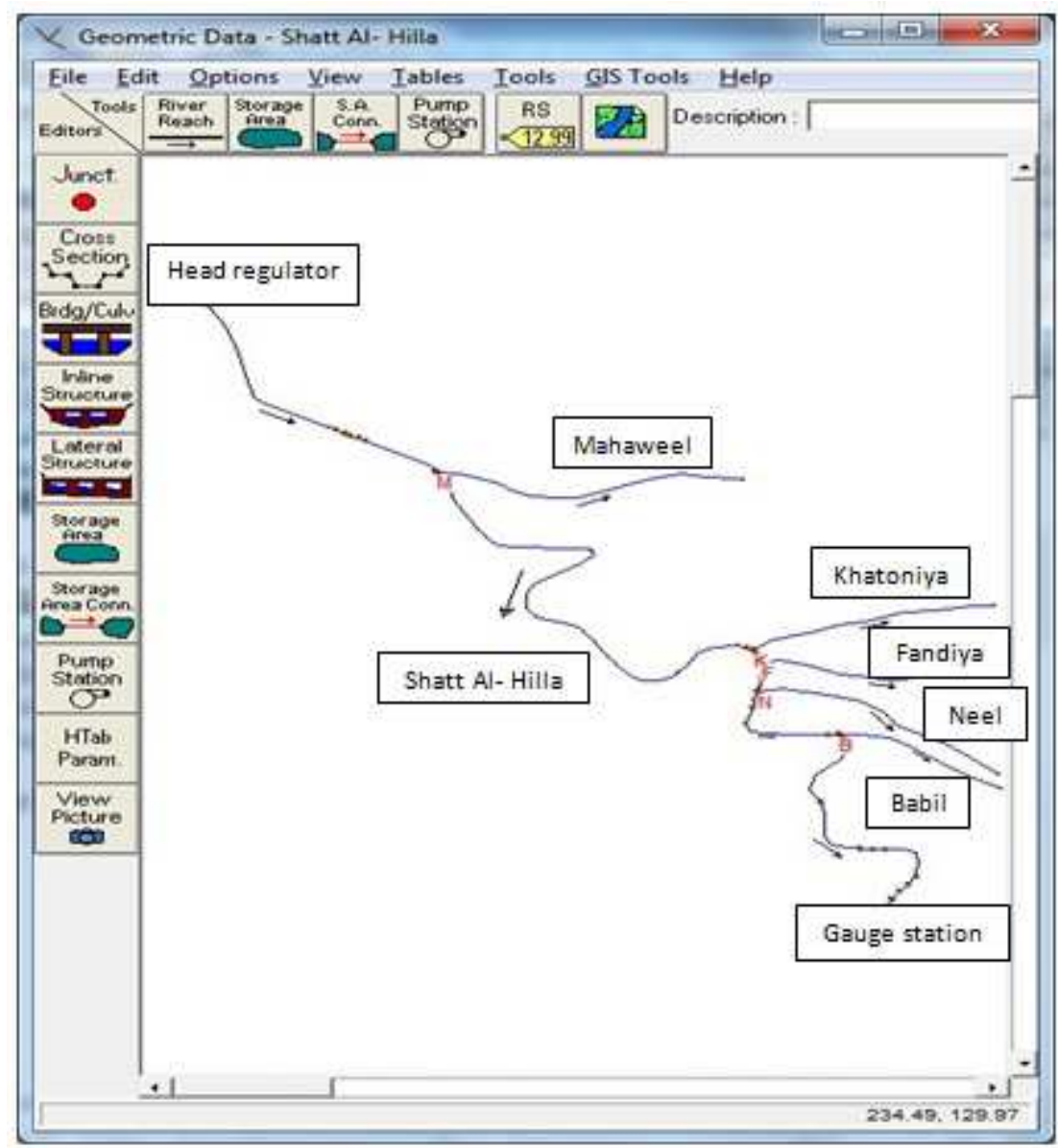

Fig. (7): Schematic of Shatt Al- Hilla system

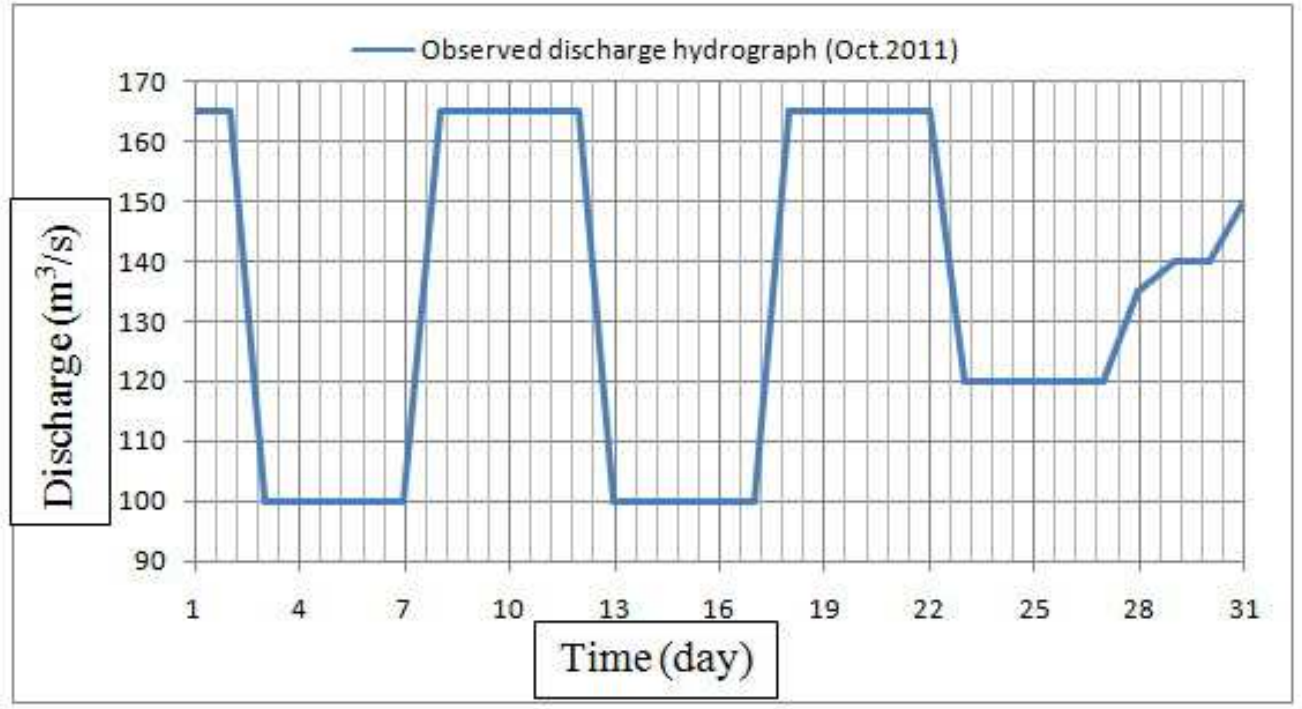

Fig. (8): Discharge hydrograph at station (1), case (1), October 2011 (upstream boundary condition) 


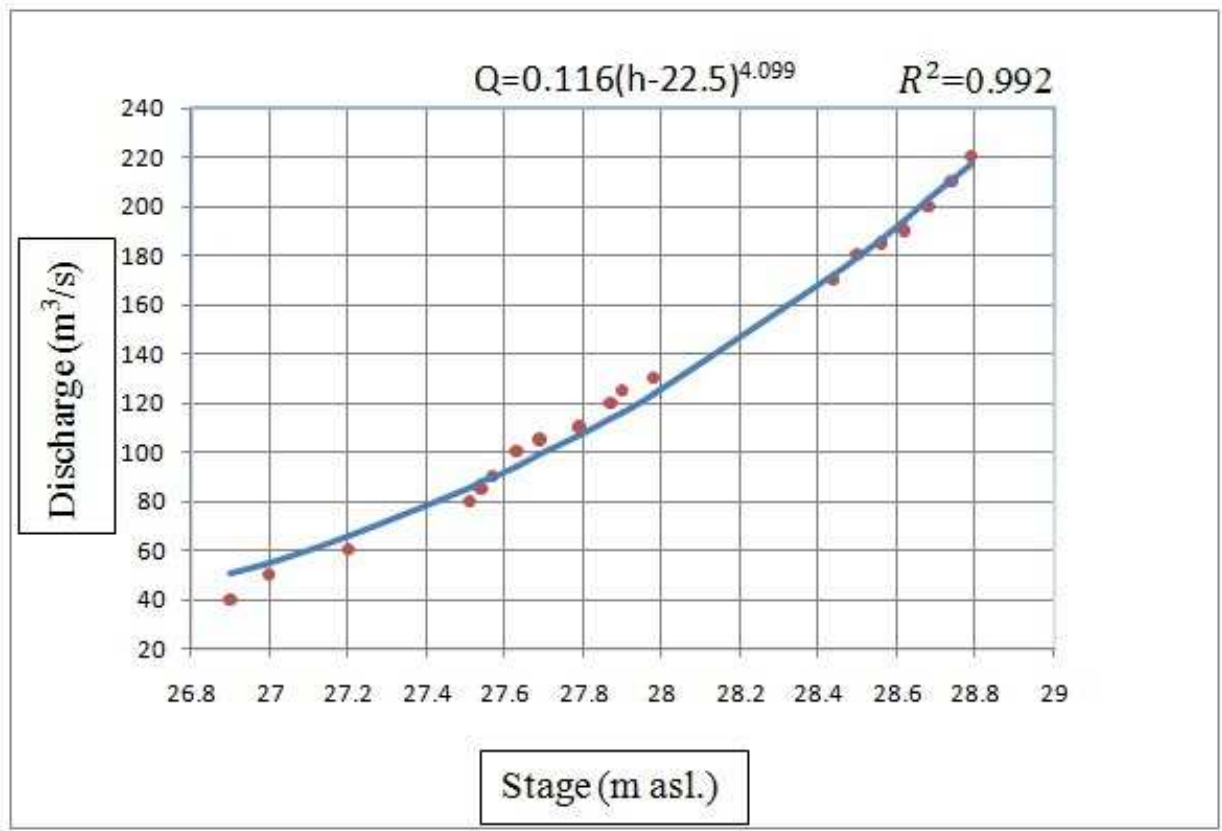

Fig.(9): Rating curve at station $(33+000)$

The best fit equation is:

$$
Q=0.116(h-22.5)^{4.099}
$$

Where $\mathrm{h}=$ water surface elevation $(\mathrm{m}$ asl.) and $\mathrm{Q}=$ discharge $\left(\mathrm{m}^{3} / \mathrm{s}\right)$.

\subsubsection{Limitations and Assumptions of the Present study}

The following limitations and assumptions are considered in this research:

I. It is limited to the case where the basic assumptions of Saint-Venant equations are valid.

II. In channel flow routing, the source term, i.e., rainfall, is normally neglected since the amount of rainfall in the channel is very small in comparison with channel flow.

III. In channel flow routing, the sink term, i.e. seepage, is neglected since the channel bed is saturated and the loss of water due to the seepage is negligible.

IV. The Manning's roughness coefficient (n) is assumed to remain constant with time and distance along Shatt Al-Hilla River.

\subsubsection{Stage Hydrographs at Section (50)}

The stages of water at section (50) for the three cases 1 , 2 and 3 are obtained by routing Shatt Al-Hilla using HECRAS model. The results will show if water levels at section (50) are less than the minimum water level required or more than the maximum water level in order to start a warning system in SCADA. Additionally, knowing the daily water levels at section (50) is helpful in arranging operational schedules for the structures downstream section (50). Tables2, 3 and 4 show the calculated stages of water at section (50) at sensor $\left(\mathrm{y}_{3}\right)$ for cases 1,2 and 3 respectively.

Table (2): The calculated stages of water at section (50) at sensor ( $\left.y_{3}\right)$ for case (1)

\begin{tabular}{|c|c|c|c|c|c|c|c|c|c|c|c|c|}
\hline Month & Oct & Nov & Dec & Jan & Feb & Mar & Apr & May & June & July & Aug & Sept \\
\hline Stage (m asl) & 27.76 & 28.04 & 27.57 & 27.27 & 27.25 & 27.67 & 27.41 & 27.26 & 27.59 & 28.02 & 28.06 & 28.04 \\
\hline
\end{tabular}

Table (3): The calculated stages of water at section (50) at sensor ( $\left.y_{3}\right)$ for case (2)

\begin{tabular}{|c|c|c|c|c|c|c|c|c|c|c|c|c|}
\hline Month & Oct & Nov & Dec & Jan & Feb & Mar & Apr & May & June & July & Aug & Sept \\
\hline Stage (m asl) & 28.46 & 28.08 & 27.34 & 27.51 & 28.34 & 28.79 & 28.79 & 28.70 & 28.79 & 28.79 & 28.78 & 28.04 \\
\hline
\end{tabular}

Table (4): The calculated stages of water at section (50) at sensor ( $\left.y_{3}\right)$ for case (3)

\begin{tabular}{lcccccc}
\hline Month & May & June & July & Aug & Sept \\
\hline Stage (m asl) & 27.29 & 27.63 & 28.05 & 27.99 & 27.85 \\
\hline
\end{tabular}


In comparison with demanded water, the results obtained by routing Shatt Al-Hilla using HEC-RAS model for case (1) and case (2) indicate that there are deficits of supplied stages for all months except at January (case 2)there are surplus in stage of water leads to surplus in flow equal to $\left(15.00 \mathrm{~m}^{3} / \mathrm{sec}\right)$. In this case, SCADA system can show warning about this case to operators at Al-Hindiya Barrage in order to close the gates of head regulator of Shatt AlHilla.

\section{Discussion}

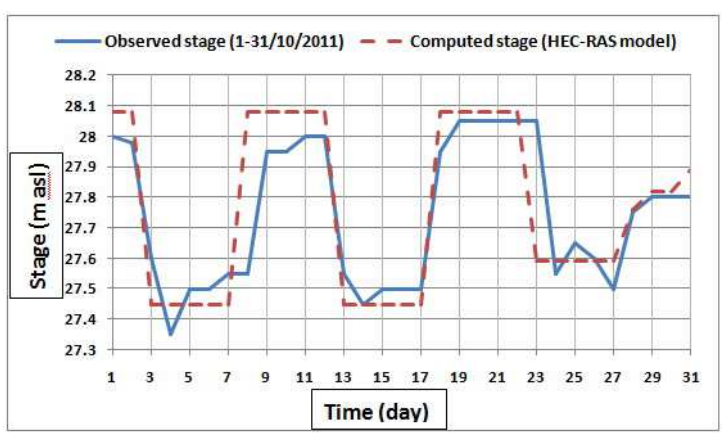

Fig. (10.1): Computed and observed stage hydrographs at section (50) $(1-31 / 10 / 2011)$

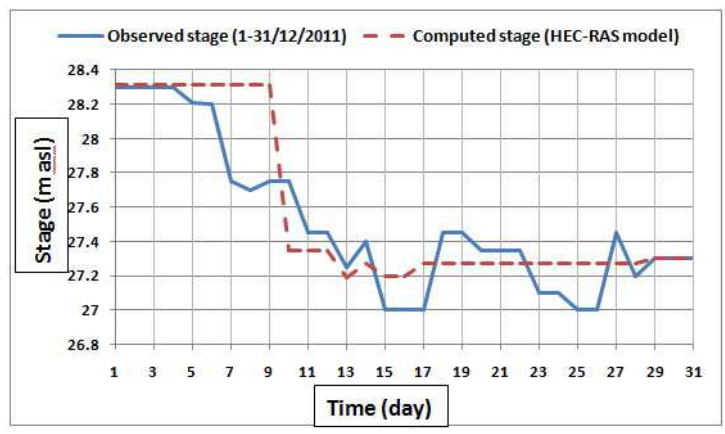

Fig. (10.3): Computed and observed stage hydrographs at section (50) $(1-31 / 12 / 2011)$

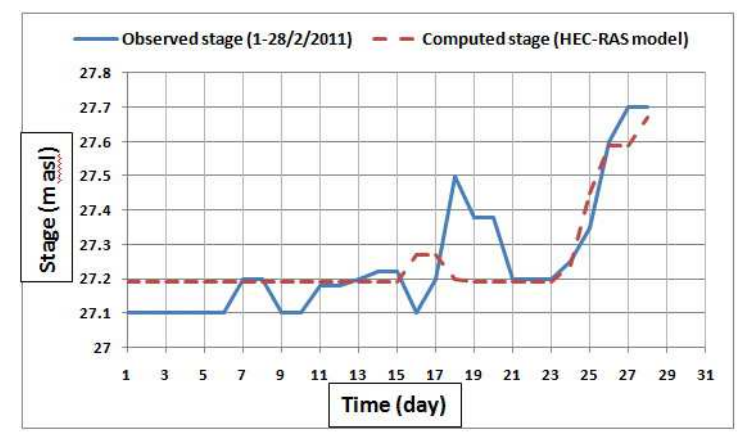

Fig. (10.5): Computed and observed stage hydrographs at section (50) $(1-28 / 2 / 2011)$

\subsection{Verification of Shatt Al-Hilla HEC-RAS Model}

The verification process of the unsteady flow model was achieved by making a comparison between the observed and computed stage hydrographs at section (50). Figs. (10.1) to (10.12) show the computed and observed stage hydrographs at section (50) for 2011. The solid line identifies the observed stage hydrograph whereas the dashed line represents the computed stage hydrograph by HEC-RAS model.

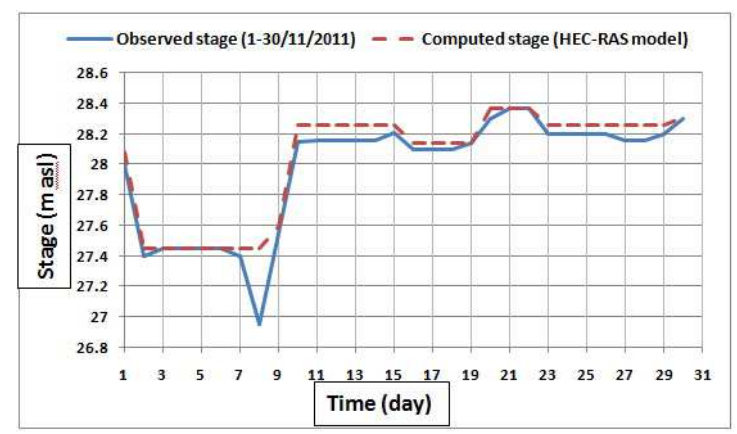

Fig. (10.2): Computed and observed stagehydrographs at section (50) (130/11/2011)

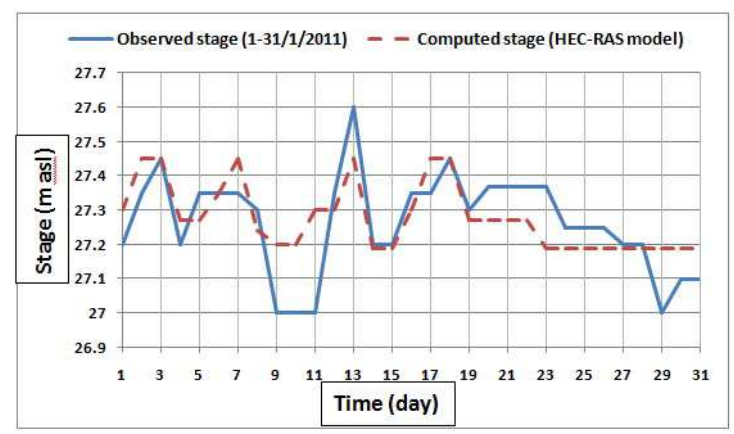

Fig. (10.4): Computed and observed stage hydrographs at section (50) $(1-31 / 1 / 2011)$

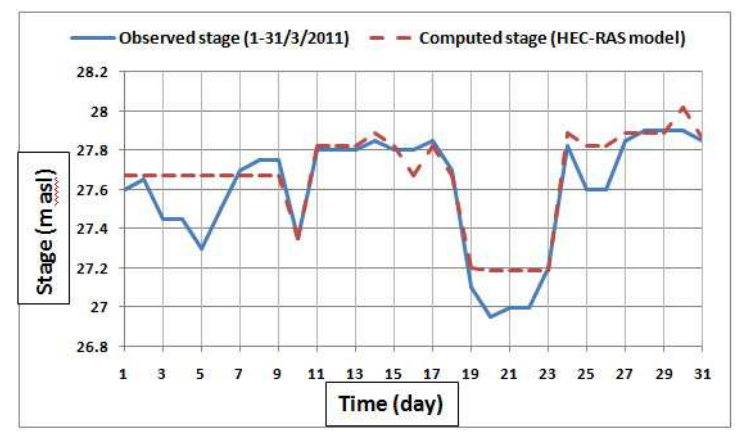

Fig. (10.6): Computed and observed stage hydrographs at section (50) $(1-31 / 3 / 2011)$ 


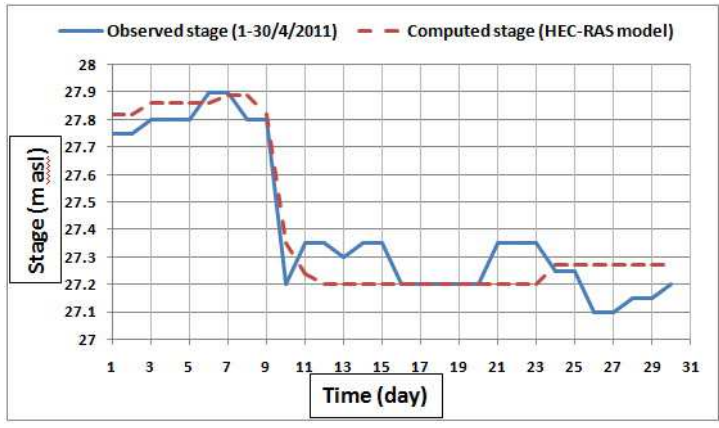

Fig. (10.7): Computed and observed stage hydrographs at section (50) $(1-30 / 4 / 2011)$

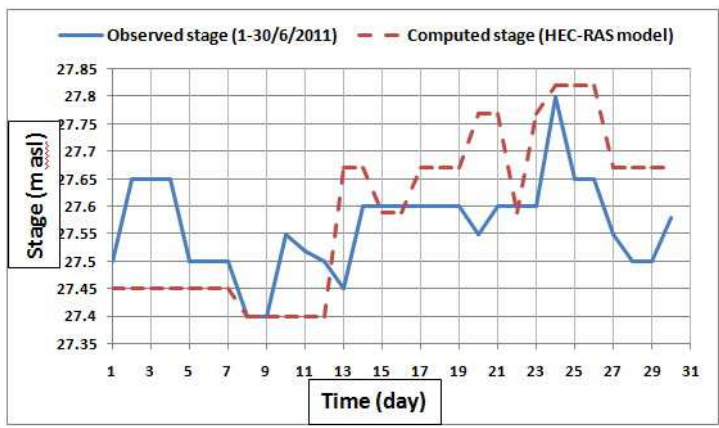

Fig. (10.9): Computed and observed stage hydrographs at section (50) $(1-30 / 6 / 2011)$

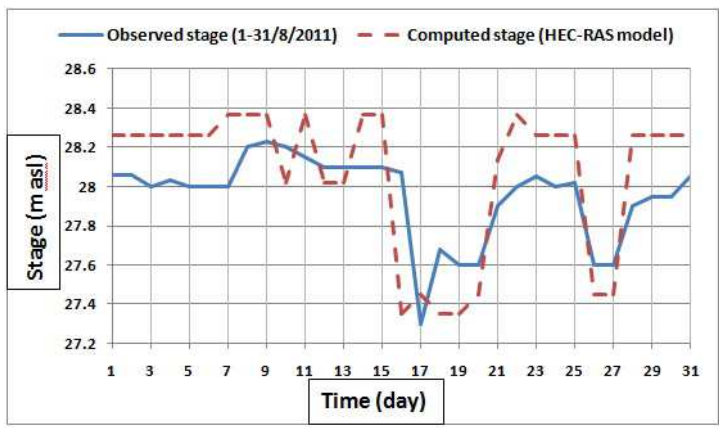

Fig. (10.11): Computed and observed stage hydrographs at section (50) $(1-31 / 8 / 2011)$

The actual observed stage hydrograph at section No.50 is appointed for the error analysis. Table (5) shows the

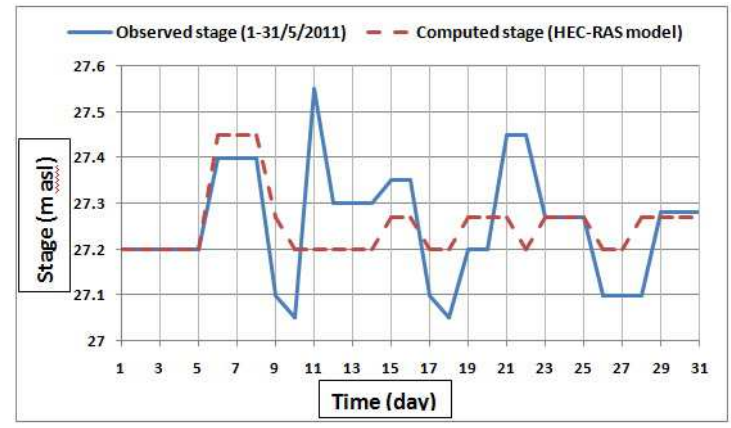

Fig. (10.8): Computed and observed stage hydrographs at section (50) $(1-31 / 5 / 2011)$

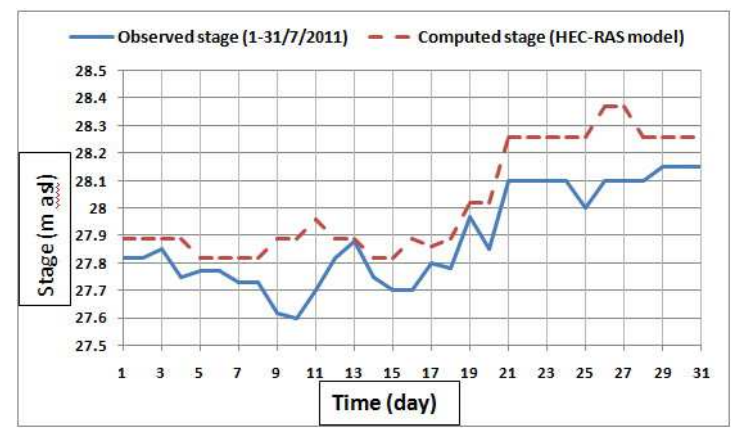

Fig. (10.10): Computed and observed stage hydrographs at section (50) $(1-31 / 7 / 2011)$

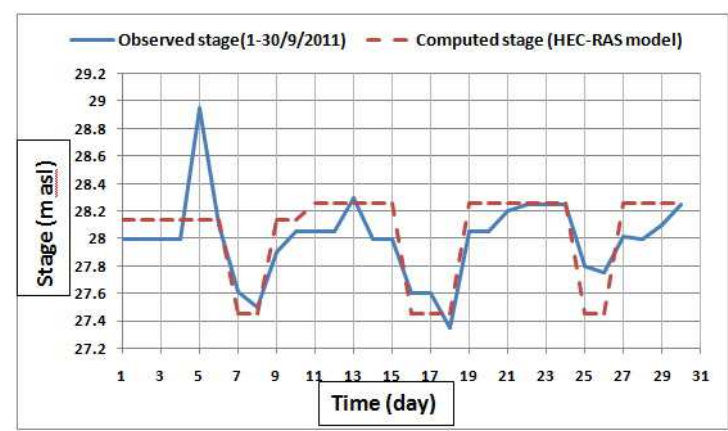

Fig. (10.12): Computed and observed stage hydrographs at section (50) $(1-30 / 9 / 2011)$

average monthly observed $\left(\mathrm{h}_{\mathrm{o}}\right)$ and computed $\left(\mathrm{h}_{\mathrm{c}}\right)$ stages at section (50) for 2011.

Table (5): The average monthly observed $\left(h_{0}\right)$ and computed $\left(h_{c}\right)$ stages at section (50) for 2011

\begin{tabular}{|c|c|c|c|c|c|c|c|c|c|c|c|c|}
\hline Month & Oct & Nov & Dec & Jan & Feb & Mar & Apr & May & June & July & Aug & Sept \\
\hline$h_{0}$ (m asl) & 27.75 & 27.97 & 27.51 & 27.26 & 27.25 & 27.60 & 27.42 & 27.26 & 27.57 & 27.89 & 27.96 & 28.00 \\
\hline$h_{c}(m$ asl $)$ & 27.77 & 28.04 & 27.58 & 27.28 & 27.25 & 27.67 & 27.42 & 27.25 & 27.60 & 28.03 & 28.07 & 28.04 \\
\hline
\end{tabular}
(3):

The root mean square error is computed according to Eq.

$$
R M S E=\sqrt{\frac{1}{n} \sum_{i=1}^{n}\left(h_{c}-h_{0}\right)^{2}}
$$


and it is equal to 0.0644 . Thus, the simulation model is very good and accepted.

\subsection{Alarms}

The SCADA alarms processing have an important role: making possible the information about verified damages, suggesting the correspondent actions and, in extreme conditions, making automatic decisions. The main alarms of the SCADA are:

I. Water depths in canals in order to prevent the canal empting or canal overtopping. Two alarms were put at section (50) (gauge station). The first alarm is in the case of decreasing water level lower than (27.19 $\mathrm{m}$ asl). The alarm is (Low water level-Open the gate) because this water level is critical and corresponds to discharge (40) $\mathrm{m}^{3} / \mathrm{s}$. This amount of discharge is essential for drinking water and to prevent the canal empting. The second alarm is in the case of increasing water level higher than (28.79 $\mathrm{m}$ asl) in order to prevent the canal overtopping. The alarm is (High water level-Close the gate).

II. The operational state of the control devices (water level and gate sensors) in case one of these devices is not working. The alarm (device is not working) is set.

\section{Conclusions}

I. Through testing many values of the hysteresis $(\Delta x)$, it is found that the value of $(0.015 \mathrm{~m})$ is suitable to this study. This value of $(\Delta x)$ gives a discharge value near $\left(3.00 \mathrm{~m}^{3} / \mathrm{s}\right)$ which satisfies any two sequence discharges for the three cases considered. The value of $(\Delta x)$ is entered to (PLC1) program in order to run the SCADA system.

II. The results obtained from the controlling of head regulator of Shatt Al-Hilla for three different cases of controlling indicate that all cases and scenarios are acceptable and suitable for application except scenario (6) in the three cases. This is because scenario (6) in the three cases depends on working one radial gate only and the maximum radial gate opening is $(5.400 \mathrm{~m})$. Therefore, there are deficits in supplying the discharges in many days through the year.

III. In case (2), the discharges for the four months Mar, Apr, June and July cannot satisfy the safe side because their discharges are higher than the maximum safe discharge $\left(247.05 \mathrm{~m}^{3} / \mathrm{s}\right)$. Therefore, there are deficits of $(1.57 \%, 16.67 \%, 18.46 \%$, and $14.04 \%$ ) of the total demanded discharges for Mar, Apr, June, and July respectively.

IV. The minimum stage at section (50) [gauge station] is $(27.19 \mathrm{~m}$ asl.) in order to prevent the canal empting, and the maximum stage is $(28.79 \mathrm{~m}$ asl.) in order to prevent the canal overtopping. These values of stages are used in the warning system for SCADA in order to give the appropriate warnings.

\section{References}

[1] Rijo M., DESIGN AND FIELD TUNING OF AN UPSTREAM CONTROLLED CANAL NETWORK SCADA, Journal of Irrigation and Drainage Engineering, 57: 123-137, 2008.

[2] Tony L. W., Incorporating Sharp-Crested Weirs into Irrigation SCADA Systems, USCID Conference on SCADA and Related Technologies for Irrigation District Modernization, Vancouver, Washington, 2005.

[3] Synchrony, Trends in SCADA for Automated Water Systems, 2001, http: \www.free_definition.com/dam.html).

[4] Beau F. and Charles B, Practical Experience with State of the art Technologies in SCADA Systems, ITRC Paper No. P

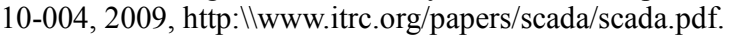

[5] James H. Graham and Sandip C. Patel, Security Considerations in SCADA Communication Protocols, Technical Report TR-ISRL-04-01, University of Louisville, 2004.

[6] Arjun V., SCADA Systems Security, 2004, http:॥ www.InfoSecWriters.com.

[7] SCED (Studies Center and Engineering Designs), Report about the expansion of Shatt Al-Hilla, (in Arabic), 2009.

[8] NCS (National Communications System), Supervisory Control and Data Acquisition (SCADA) Systems, Technical Information Bulletin 04-1, Chantilly, Virginia, 2004, http: \www. comtechnologies.com.

[9] Almeida M., Figueiredo J. and Rijo M., SCADA Configuration and Control Modes Implementation on an Experimental Water Supply Canal, Lisbon, Portugal, 2002, http: \www.canais.nuhcc.uevora.pt.

[10] GDWRM (General Directorate of Water Resources Management), Report about the Project of control system and management of adjustment structures (Al-Hindiya Barrage), Hydrological Studies Center (in Arabic), 2012.

[11] USBR (U.S. Department of the Interior Bureau of Reclamation), Water Measurement Manual, 2001.

[12] USACE (U.S. Army Corps of Engineers), Tainter Gates in Open Channels, Hydraulic Design Criteria, Volume 2, Sheets 320-4 to 320-7, 1977.

[13] Clark P., Canal Radial Gate Discharge Algorithms and their Use, Research Hydraulic Engineer, Bureau of Reclamation, Engineering Colorado 80225, 1983.

[14] HEC-RAS (River Analysis System), User's Manual, Version 4.1, U.S. Army Corps of Engineers, Hydrologic Engineering Center, Davis, California, 2010.

[15] Chow V.T., Maidment, D.R. and Mays, L.W., Applied Hydrology, McGraw-Hill, New York, 1988. 